\title{
Needs assessment of mental health training for Auxiliary Nurse Midwives: a cross-sectional survey
}

\begin{abstract}
Mental health in pregnant women and new mothers is increasing recognised on the global health agenda. In Nepal mental health is generally a difficult to topic to discuss. THET, a London-based organisation, funded Bournemouth University, and Liverpool John Moores University in the UK and Tribhuvan University in Nepal to train communitybased maternity workers on issues around mental health.
\end{abstract}

This paper reports on a quantitative survey with nearly all Auxiliary Nurse Midwives in Nawalparasi (southern part of Nepal). The findings illustrate the lack of training on mental health issues related to pregnancy and childbirth in this group of health workers. Thus the paper's conclusions stress the need for dedicated training in this field.

\section{Introduction}

Mental health is in many ways a difficult topic to discuss in Nepali society. [1] This makes it hard for health workers, especially the more general of them (i.e. non-mental health specialists), to start a discussion about stress, anxiety and other mental health issues with their patients. Mental health around childbirth has additional issues compared to the mental health of non-pregnant women who are of childbearing age. Women are often still considered second-class citizens in Nepali society, especially in the more rural areas. The epidemiological data shows that suicide is now the key risk factor of premature death for women of childbearing age, a key issue raised in this journal. [2]

In addition, pregnant women in rural Nepal are generally young and living withthe family of their husband. The pregnant woman's mother-in-law is often the person making decisions about the pregnant woman's care-seeking behaviour. [3] At the
Bibha Simkhada ${ }^{1}$, Geeta Sharma ${ }^{2}$, Samridhi Pradhan ${ }^{3}$ Edwin van Teijlingen ${ }^{4}$, Jillian Ireland ${ }^{5}$, Padam Simkhada ${ }^{6}$, Bhimsen Devkota ${ }^{7}$ and the THET team.

Liverpool John Moores University\& Visiting Faculty Bournemouth University, UK.

Green Tara Nepal

3 Green Tara Nepal, Kathmandu, \&Visiting Faculty Bournemouth University, UK.

Professor, CMMPH, Bournemouth University, UK \&Visiting Professor,Manmohan Memoriallnstitute of HealthSciences (MMIHS),

Midwife, Poole Hospital NHS Foundation Trust \&Visiting Faculty Bournemouth University, UK.

Professor, Centre for Public Health, Liverpool John MooresUniversityVisiting Professor, Manmohan Memorial Institute of Health Sciences (MMIHS),\&Visiting Faculty Bournemouth University, UK.

Professor, Department of Health, Physical and Population Education at Tribhuvan University, Nepal

Corresponding author:

Dr.Bibha Simkhada

Research Associate

Centre for Public Health, Liverpool John Moores University

Henry Cotton Building,

Webster Street

United Kingdom

B.D.Simkhada@limu.ac.uk

same time too many people have little or no antenatal care, i.e. the opportunity to consult with maternity care providers.

In terms of maternity care providers, Nepal does not have properly trained midwives.[4-5]The Auxiliary Nurse Midwives (ANMs), who are the key maternity service providers in rural birthing centres of Nepal, have received only 18 months of training and the training curriculum does not refer to dealing with mental health issues. Auxiliary nurse midwives are first point of contact in the local community during pregnancy and childbirth.[6]This mental health training covers everything the ANMs need to know about mental health basics. 


\section{The programme}

In 2015 the UK (United Kingdom)funded our THET application to take expert volunteers to Nepal to train community-based maternity care providers. [7]As part of this THET-funded programme to ANMs on

\section{Methods}

The main aim of the training is to assess the knowledge of the ANMs concerning perinatal mental health issues and identify the need for future training. Therefore, we conducted a short quantitative crosssectional study,[8]using a structure questionnaire in Nepali (copies of questionnaire are available from the first author). The questionnaire was distributed at the start of the training. The questions covered This project applied for and received ethical approval from the Nepal Health Research Council.

\section{Results}

In total 74 questionnaires were returned out of a possible 76 attendees. This is a high response rate of $97 \%$. The questionnaire is grouped in two categories for the purpose of analysis. Table 1 shows correct answers about general mental health mental health issues related to pregnancy, we conducted a needs assessment with ANMs (and a few staff nurses) working in public birthing centres of Nawalparasi district, Nepal.

issues around knowledge, community perspectives on mental health and illness and previous training on the topic. The questionnairedesign was based on the literature on mental health in pregnancy and the experience of the Nepali THET project team members. With the small sample only basic descriptive statistics could be applied.[9]

knowledge statement. Of the 74 respondents, 72 were ANMs and two were staff nurses. These two staff nurses were the only ones who said yes to the question "Have you ever had training on perinatal mental health in your job/work?"

\section{Table 1: Pretest questionnaire results}

\begin{tabular}{|l|l|l|}
\hline \multicolumn{1}{|c|}{ Question: } & $\begin{array}{l}\text { Correct } \\
\text { answer }\end{array}$ & $\begin{array}{l}\text { Answered } \\
\text { correctly }\end{array}$ \\
\hline $\begin{array}{l}\text { Mental illness is common - about one in five adults experience a } \\
\text { mental disorder at some stage in their life. }\end{array}$ & Yes & $46(62 \%)$ \\
\hline Mental illness cannot affect children or young people. & No & $60(81 \%)$ \\
\hline $\begin{array}{l}\text { You can tell by looking at a person whether they are experiencing a } \\
\text { mental illness. }\end{array}$ & No & $38(51 \%)$ \\
\hline $\begin{array}{l}\text { Mental disorders are always long-term conditions that can never be } \\
\text { fully cured. }\end{array}$ & No & $56(75 \%)$ \\
\hline People with mental illness are not capable to work. & No & $59(80 \%)$ \\
\hline People with mental illness often need help to recover. & Yes & $73(99 \%)$ \\
\hline ANM can help to reduce stress level in pregnant women. & Yes & $73(99 \%)$ \\
\hline Mental illness is the result of possession by evil spirits or karma. & No & $71(96 \%)$ \\
\hline Mental illness can be caused by: stressful life events. & Yes & $74(100 \%)$ \\
\hline Mental illness can be caused by: abuse & Yes & $73(99 \%)$ \\
\hline Mental illness can be caused by: pregnancy and childbirth & Yes & $37(50 \%)$ \\
\hline $\begin{array}{l}\text { When a mental disorder is suspected, have the person admitted to a } \\
\text { psychiatric hospital or give medication immediately }\end{array}$ & No & $46(62 \%)$ \\
\hline
\end{tabular}


\begin{tabular}{|l|l|l|}
\hline People with mental illness are seen as mad people in my community. & Yes & $49(66 \%)$ \\
\hline
\end{tabular}

In order to be able to set our mental health and maternity care training at the appropriate level we asked ANMs about their experience concerning training and mental health issues in their own communities (Table 2).

Table2: ANM training and experience of practice

\begin{tabular}{|l|l|}
\hline Question: & N (\%) \\
\hline $\begin{array}{l}\text { We have learnt skills to manage people with mental illness in } \\
\text { our nursing training. }\end{array}$ & $55(74 \%)$ \\
\hline We get in-service training on mental health. & $54(73 \%)$ \\
\hline $\begin{array}{l}\text { People talk openly about mental health problem in my local } \\
\text { community. }\end{array}$ & $8(11 \%)$ \\
\hline $\begin{array}{l}\text { People with mental problems seek help with health providers for } \\
\text { prevention and cure in my community. }\end{array}$ & $50(67 \%)$ \\
\hline No one is there to help me when I am stressed. & $34(46 \%)$ \\
\hline
\end{tabular}

Respondents were also asked what they expected from the training, their replies are outlined in Table 3.

Table 3: Expectations of the participants from the training:

Expectations from the training:

- Gain in-depth knowledge on mental health

- Learn about mental problems, their symptoms and management

- Be able to raise awareness in the community regarding mental health

- Learn best ways to give counselling services to people living with mental problems

- Learn about mental problems that could arise during prenatal and postnatal period

- Learn new things on mental health

- Be able to identify mental health related complications during and after childbirth

- Be able to identify the cases of mental health related problems

- Be able to learn new things on taking care of the new-born

- Learn about causes and management of mental stress

- Be able to practice the things learned in the training

- Know the causes of mental problems/illnesses

- Learn about the situation of mental health in the community

Overall knowledge of basic mental health issues was good, however, knowledge and skills of recognising mental health problems and illnesses was found to be poor. The result of the pre-test questionnaire 


\section{Original Article}

shows that almost half of the ANMs believed that people experiencing a mental illness can be diagnosed by looking at the person. Similarly, they also believed that whenever a mental disorder is suspected, the suspected needs to be admitted to a psychiatric hospital or given medication immediately.

Their knowledge on perinatal mental health was poor, half of the nurses were not aware that pregnancy and childbirth could cause mental illnesses. However, the majority of them claimed that they can help to reduce mental health problems with appropriate training. The majority of the participants also reported that people do not talk openly about mental health problems in their local community but also over half of them reported that people with mental health problems seek help with health providers for prevention and cure.

Nearly three-quarters (73\%) of ANMs had undergone some mental health training in their nursing training

\section{Discussion}

The participants in the initial training highlighted that there is huge disrespect for people with mental health problems in the community. People with mental health problems are highly stigmatized and mistreated.[10]The result of this study also shows that there is a taboo on mental health and that people hardly talk about it due to the stigma associated to it and may therefore hesitate to seek help. Asystematic review in other developing countries also shows that the fear of stigma can make women and their families reluctant to seek care.[11]Therefore, it is important to reduce stigma in order to improve mental health service utilisation. The ANMs could be used as key persons to raise awareness formental health stigma at the community and in their nursing job. At the same time nearly all (97\%) reported that they never had training that is specific to perinatal mental health which is very important for ANMs as they have to deal with these issues in their everyday life at work.

After pre-test we also asked them to write some expectations from the training they were planning to attend. They highlighted some issues around mental health, symptoms and management as well as skills to raise awareness in their local community, counselling skills, issues surrounding perinatal mental health problems and the skills to identify mental health related complications during pregnancy and after childbirth. Once identified they hopefully will be able to refer the more severe cases on to more specialist care providers. They also expected to learn new skills on taking care ofthe mother and her new born baby in their day to day practice.

level. Improved knowledge on perinatal mental health of frontline health workers is important as many women during pregnancy and childbirth are suffering with mental health problems.[12] The participants also highlighted the need for improved knowledge and skills on the management of perinatal mental health problems as well as early diagnosis and treatment during this period. They desire to improve their abilities of raising awareness and prevention/counselling skills for psychological treatment at the local level.

Throughout the training they also discussed the problems and challenges related to mental health problems during pregnancy and childbirth where 
women have low autonomy.[3,13] ANMS highlighted that there is need for perinatal mental health training for skilled nurses to manage mental health problems and related complications at the community level. Counselling skills and awarenessraising skills were mentioned as key skills needed for frontline health service providers to promote mental health and wellbeing in the community. In addition they have emphasized various skills highlighted in the Table 3. This issue was also recognised in a conclusion

The ANMs in Nawalparasi had received little or no formal training on perinatal mental health issues, either during their basic training or during any followup training on the job. This study found that there is need for perinatal mental health training to improve

\section{Acknowledgements}

We like to thank all ANMs for participating in the study and we are grateful to the NHRC for granting ethical approval.Funding was provided to theDepartment of Health, Physical and Population Education at Tribhuvan University's (TU) and two UK universities Bournemouth University and Liverpool John Moores University (LJMU) have been awarded a grant under the Health Partnership Scheme (HPS). recent WHO (World Health Organization)report with other partners, namely that perinatal mental health often requires complex skills due to a lack of human resources in Nepal.[14] Furthermore, other countries also suggest nurses and midwives need to be competent to help pregnant women and new mothers to prevent mental health problems and provide early treatment to reduce complications.[1516]

their knowledge for their daily nursing practice. The THET project is a timely and appropriate training which aims to fulfil the gap in the knowledge of ANMs concerning perinatal mental health

HPS funds health partnerships to carry out training and capacity-building projects in low-income countries, such as Nepal. HPS itself is funded by the UK Department for International Development (DfID) and managed by THET (Tropical Health \& Education Trust).We thank Mr. Cameron van Teijlingen for proof-reading the final draft of this paper. 


\section{Original Article}

\section{References}

1. Brenman N F, Luitel NP, Mall A,Jordans MJD Demand and access to mental health services: a qualitative formative study in Nepal. BMC International Health \&Human Rights,2014; 14:22.

2. Simkhada, P., van Teijlingen E.,Winter, R.C., Fanning, C., Dhungel, A., Marahatta S.B.(2015) Why are so many Nepali women killing themselves? A review of key issuesJournal of Manmohan Memorial Institute of Health Sciences 2015; 4(1): 43-49. http://www.nepjol.info/index.php/JMMIHS/article/view/12001

3. Simkhada, B., Porter, M., van Teijlingen, E. The role of mothers-in-law in antenatal care decision-making in Nepal: A qualitative study.BMC Pregnancy \& Childbirth2010; 10(34)www.biomedcentral.com/content/pdf/1471-2393-10-34.pdfAccessed March 2016.

4. Bogren $M$, van Teijlingen $E$. Berg $M$. Where midwives are not yet recognized: A feasibility study of professional midwives in Nepal, Midwifery 2013; 29(10): 103-1109.

5. Bogren, M.U., Bajracharya, K., Berg, M., Erlandsson, K., Ireland, J., Simkhada, P., van Teijlingen, E.Nepal needs midwifery, Journal of Manmohan Memorial Institute of Health Sciences (JMMIHS)2013;1(2): 41-44. www.nepjol.info/index.php/JMMIHS/article/view/9907/8082Accessed March 2016.

6. Morrison J, Tumbahangphe KM, Budhathoki B, Neupane R, Sen A, et al. Community mobilisation and health management committee strengthening to increase birth attendance by trained health workers in rural Makwanpur, Nepal: study protocol for a cluster randomised controlled trial. Trials 2011; 12:128. [http://www.trialsjournal.com/content/12/1/128]. Accessed March 2016.

7. van Teijlingen, E., Simkhada, P., Devkota, B., Fanning, P., Ireland, J., Simkhada, B., Sherchan, L., Silwal, R.C., Pradhan, S., Maharjan, S.K., Maharjan, R.K. (2015) Mental health issues in pregnant women in Nepal. Nepal Journal of Epidemiology5(3): 499-501. http://www.nepjol.info/index.php/NJE/article/view/13607/11007

8. Brindle S, Douglas, F, van Teijlingen E., Hundley V. (2005) Midwifery Research: Questionnaire surveys, RCM Midwives Journal 2005;8(4): 156-158.

9. Hebl, M. (2016) Descriptive Statistics. In: Lane, D.M. (ed.) Introduction to Statistics Online Edition (available at: http://onlinestatbook.com/2/index.html ; accessed March 2016).

10. Luitel NP, Jordans MJD, Adhikari A, Upadhaya N, Hanlon C, Lund C,Komproe IH. Mental health care in Nepal: current situation andchallenges for development of a district mentalhealth care plan. Conflict and Health 2015; 9:3.

11. RahmanA,FisherJ, Bower P, Luchters S, Tran T, Yasamy MT, Saxena S,Waheed W. Interventions for common perinatal mental disorders in women in low- and middle-income countries: a systematic review and meta-analysis. Bulletin World Health Organization, 2013;91: 593-601.

12. Subba NR. Post-Partum Depression among Rajbansi Women in Nepal. Researcher: A Research Journal of Culture and Society. 2013; 1(1). http://nepjol.info/index.php/RESEARCHER/article/view/8374 Accessed Jan 2016.

13. Acharya, D.R., Bell, J., Simkhada, P., van Teijlingen, E,Regmi, P.R. (2010) Women's autonomy in decision-making for health care: A demographic study in Nepal. Reproductive Health 9(15) www.reproductive-health-journal.com/content/pdf/1742-4755-7-15.pdf

14. Ministry of Health and Population Nepal, Partnership for Maternal, Newborn \& Child Health, WHO, World Bank and Alliance for Health Policy and Systems Research. Success factors for women's and children's health: Nepal. Geneva: World Health Organisation,2014.

15. NICE. Antenatal and postnatal mental health:clinical management and serviceguidance. Clinical guideline. National Institute for Health and Care Excellence, 2014. http://www.nice.org.uk/guidance/cg192/resources/antenatal-and-postnatal-mental-health-clinicalmanagement-and-service-guidance-35109869806789. Accessed Feb 2016. 
16. Royal College of Midwives. Caring for Women withMental Health Problems: Standards and Competency Framework forSpecialist Maternal Mental Health Midwives. London: The Royal College of Midwives, 2015.

https://www.rcm.org.uk/sites/default/files/Caring\%20for\%20Women\%20with\%20Mental\%20Health\%20Dif ficulties\%2032pp\%20A4 h.pdfAccessed Feb 2016. 